\title{
The Pronunciation of Women: Some Spanish Evidence
}

Lynn Williams

lynn_williams@byu.edu

Follow this and additional works at: https://scholarsarchive.byu.edu/facpub

Part of the Spanish and Portuguese Language and Literature Commons

\section{Original Publication Citation}

Williams, L. "The Pronunciation of Women: Some Spanish Evidence", Language \&

Communication, Vol. 3, No 2 (1983), pp.171-9.

\section{BYU ScholarsArchive Citation}

Williams, Lynn, "The Pronunciation of Women: Some Spanish Evidence" (1983). Faculty Publications. 1208.

https://scholarsarchive. byu.edu/facpub/1208

This Peer-Reviewed Article is brought to you for free and open access by BYU ScholarsArchive. It has been accepted for inclusion in Faculty Publications by an authorized administrator of BYU ScholarsArchive. For more information, please contact ellen_amatangelo@byu.edu. 


\title{
THE PRONUNCIATION OF WOMEN: SOME SPANISH EVIDENCE
}

\author{
LYNN WILLIAMS
}

\section{Introduction}

The material for this article has been drawn from a larger sociolinguistic survey of various aspects of the phonology of 18-26 yr olds in Valladolid carried out between October 1976 and April 1977. ${ }^{1}$ The methodology used is basically the same as that developed by William Labov for his New York survey and has become one of the most established methods of enquiry into the social differentiation of the phonology of urban speech-communities. Informants were selected from the Valladolid census records in a semi-random manner and assigned to their socio-economic class according to the criteria of Spanish sociologists. Each informant was interviewed with the aid of a questionnaire designed to elicit speech characteristic of four distinct contextual styles. The different sections into which the questionnaire was divided are conversation style (CS), reading-passage style (RPS), word-list style (WLS) and minimal pairs style (MPS) and represent increasing degrees of formality and attention paid to speech as the interview progressed. All interviews were tape-recorded. ${ }^{2}$

Each phonological variable was identified together with all its variants during the course of a pilot survey. The variants were arranged in a sociolinguistic hierarchy according to the degree of prestige attached to them and then allotted numerical values. A low value was given to the traditional, prestige variant with higher values being allotted to each remaining variant as the amount of prestige connected with it decreased. This numerical scale makes it easy for those unfamiliar with the Valladolid speech community to identify the position of variants within their respective sociolinguistic hierarchies.

Labov goes further than this in his survey and uses the numerical scale as the basis for converting phonological data into statistical data which take the form of index scores. These index scores represent a sort of average score achieved by informants for a particular phonological variable in a given social context. By extending the operation, Labov calculates index scores for the different socio-economic groups in several contextual styles and presents the data, coarsened in this way, in the form of a graph which immediately gives an indication of the nature of the sociolinguistic variation involved. This is a neat and space-saving method of presenting data of this type and where the phonological variable concerned has only two variants one gets a good idea from the index score of the behaviour of both variants. However, where a variable has three or more variants, Labov's method begins to conceal much of the data because it then becomes impossible to determine how the different variants of a variable combine to give an index score and scores which appear in the middle range of the index are particularly confusing. One method which has been used to overcome this difficulty has been to present the number of times each variant of a variable occurs as a percentage score of the total number of occurrences of that variable as observed among a particular socio-economic group in a given contextual style. This method has the advantage of presenting the data more or 
less in raw form and of revealing in detail what is happening. The use of raw data, however, can create almost as many problems as it solves. For example, rather more space is often required for the tabulation of results. Also, results in this form tend not to lend themselves to immediate interpretation as general patterns are frequently obscured by detail. This problem becomes more and more acute as the number of variants to be looked at rises and one begins to discover some of the virtues of Labov's index score which maintains the same level of efficiency, such as it is, for all variables having three or more variants as I have explained. The dilemma, then, is how to present data in a way that will allow the behaviour of all the variants of a variable to be observed while at the same time giving an indication of the general sociolinguistic patterns prevailing in the community under study. So far as I know, no adequate solution to the problem has yet been reached. What $\mathrm{I}$, therefore, propose to do here is to present, in table form, percentage scores for all the variants of each variable as they are used by the various socio-economic groups in different social contexts and then, in my analysis of the behaviour of each variable, to coarsen the results as I attempt to extract general conclusions from them. A certain coarsening of the data, it seems to me, is inevitable if one is to have anything worthwhile to say.

Another point of departure between Labov and myself has to do with how to define a 'speech community'. This is important because it is related to the patterns of stylistic variation found in New York and Valladolid. Labov (1966, p. 288) believes it feasible to define a speech community as 'a group of speakers who share a set of social attitudes towards language'. By this he means that all speakers in a given speech community, regardless of their socio-economic class, agree on what is 'correct' or 'prestigious' as far as linguistic usage in their community is concerned and this irrespective of whether they normally use the forms they consider prestigious. It is this uniform set of subjective attitudes to language, this recognition on the part of all speakers of an exterior standard of correctness which, according to Labov, governs stylistic variation and causes all speakers to reduce the number of stigmatized linguistic forms they use as they move from an informal to a more formal situation. If this movement is plotted graphically, there is a regular downward slope from the informal to the formal. This is known as 'regular style-shifting'. Two more things regarding the Labovian view on attitudes to language within a speech community need to be mentioned before looking at the situation which obtains in Valladolid. First, because linguistic change takes place in time, Labov is forced to recognize that different generations may not always share the same set of social attitudes towards language. This can be seen as an exception to his definition of 'speech community'. Secondly, Labov also points to the existence of 'covert prestige', which, in certain contexts, can be associated with non-standard forms of language. Typical manifestations of this type of prestige are working-class (WC) or Black American linguistic solidarity. But, Labov seems to argue, this kind of prestige is not overtly expressed and, therefore, does not affect stylistic variation. The assumption is that stylistic variation responds not to covert but only to overt pressures. Covert attitudes must be elicited in other ways.

In Valladolid, I discovered that, when questioned directly with regard to pronunciation differences within their city, most, if not all, speakers tended to agree either that there were no differences or that these were minimal. However, I discovered a very obvious anomaly between this kind of attitude and the eagerness of many members of the community to pass social comment on the pronunciation of others. For example, if one asks the average 
middle-class (MC) vallisoletano to evaluate the pronunciation of a third person, one of three replies will almost certainly be given. If the speech of the third person corresponds with that of the individual being questioned, the answer is usually 'habla bien' or 'habla normal. If, on the other hand, the speech of the third person differs sociolinguistically from that of the individual being questioned, one of two replies tends to be given. Either it will be said of the third person that 'es un cursi' or that 'es un paleto'.

The terms 'cursi' and 'paleto' are diametrically opposed and are used to describe forms of social behaviour. They might equally be used to describe the way a person speaks, dresses or even eats. Both terms are pejorative and would never be used by an MC speaker in reference to himself. They are employed to condemn types of behaviour which are deemed unacceptable, either because they are felt to be pretentious or because they are considered unsavoury. Neither term need represent objective values and often simply reflects the personal taste of the user. Thus 'cursi' is a word which defines the kind of behaviour which, in its attempt to appear refined or elegant, could be thought to go too far, becoming affected or ridiculous. In the words of Francisco Umbral (1978, p. 169), 'lo cursi es siempre un exceso, algo que sobra'. Similarly, 'paleto' is also used to condemn social behaviour, but at the other end of the spectrum. It describes what is considered to be a complete lack of attention to, or ignorance of, the minimal requirements of 'good taste'. Following Umbral, it could be said that 'lo paleto es siempre deficitario, algo que falta'.

Looking more specifically at pronunciation, one can see how, in Valladolid, the use of these terms often constitutes a dialectic which reflects a state of sociolinguistic polarity. For example, use of 'cursi' is not, as might be expected, peculiar to those who wish to describe the more refined speech of someone from a higher social class; neither is 'paleto' used only by those who attempt to evaluate the more casual or substandard speech of someone from a lower social class. Vallisoletanos frequently use both words to refer to the language of members of their own social class. Now, this overtly expressed division in attitudes towards the variants of certain phonological variables in Valladolid is, for obvious reasons, particularly common amongst MC speakers. ${ }^{3}$ One MC speaker may, for example, prefer to say 'abandonado' and 'cerrado', believing this to be the only 'correct' way to pronounce this variable, whilst another speaker, of identical social characteristics, may find such conservatism stilted or affected and prefer the forms 'abandonao' and 'cerrao'. This sort of division in attitudes is applicable to a whole series of phonological variables. In short, one of two sociolinguistic trends appears to characterize the pronunciation of speakers of Valladolid Spanish. Either they follow traditional, prestige patterns or they prefer to speak a more natural, relaxed Spanish. Those who fail to recognize traditional norms are considered 'paletos' by those who continue to respect them, whilst those who reject more spontaneous forms of pronunciation are deemed 'cursis' by those who prefer a less contrived style of language. It should be noted at this point that a particular speaker need not adopt the same attitude towards all variables. Much depends on the degree to which the traditional, prestige variant of a given variable is being challenged by other variants. However, the speaker who generally adopts a relaxed approach to language tends, in the main, to handle all variables in a similar way. This, in essence, is what I have called the 'Cursi-Paleto' dialectic.

Now, the state of sociolinguistic polarity encapsulated in the 'Cursi-Paleto' dialectic 
allows us to draw two conclusions. First, contrary to accepted popular opinion within and without the community, there are differences in pronunciation in Valladolid which are sociolinguistically significant. Secondly, it must be remembered that the 'CursiPaleto' dialectic reflects overt attitudes to language and has little, if anything, to do with covert prestige. Amongst vallisoletanos of the same age, and even of the same socioeconomic group, there are two sets of overt subjective attitudes to some phonological variables. By this I mean that often there is no uniform agreement as to which variant of a variable has the greatest prestige. This evidently conflicts with the Labovian view that, providing they belong to the same age-group, all speakers in a given speech community, regardless of their socio-economic class, will share a common set of attitudes to language. But apart from casting doubt on the accuracy of Labov's definition of 'speech community', the 'Cursi-Paleto' dialectic is also important because, inevitably, it upsets the regular pattern of stylistic variation that we find in the New York survey. If, as Labov seems to propound, stylistic variation, as a speaker moves from an informal to a more formal context, responds to overt pressures, to the recognition on the part of all speakers of a single exterior standard of correctness, then the existence in Valladolid of two sets of overt subjective attitudes towards some variables is unlikely to produce this same regular pattern. In fact, the pattern of stylistic variation that we find in Valladolid sometimes conforms to the Labovian pattern and sometimes does not. In those cases where the position of the traditional, prestige variant of a variable remains secure, i.e. where there is only one exterior standard of correctness, there is no division in subjective attitudes towards the variable, and the orthodox pattern of stylistic variation found in Labov obtains. But where the position of the traditional, prestige variant is challenged by a new form which gains recognition amongst a sufficient number of speakers, particularly those of the highest socio-economic group, there is a division of subjective attitudes towards the variable, and the orthodox pattern of stylistic variation is disrupted. The division in subjective attitudes may manifest itself along social class or sex lines, or simply between individuals in the same social group, and the disruption of the pattern is seen in the reversal in the direction of stylistic variation between WLS and MPS, because it is only in MPS that the informant is required to make a conscious choice between two competing forms as, for example, in the minimal pair 'bacalao' and 'abandonado' 2 . Nowhere else is he required to make such a choice. The direction which the grapli iakes between these two styles indicates whether the new form is beginning to triumph or whether the traditional, prestige variant is thus far resisting the challenge to its position.

To sum up, then, the pattern of stylistic variation found in Valladolid may not always be orthodox but is important because it reflects the status of competing sociolinguistic trends and indicates which of the trends is triumphing in each of the phonological variables at the time the survey was conducted.

\section{Female speech}

Otto Jespersen is often cited as one of the first scholars to comment on sex differences in language. He has defined female speech as being refined, euphemistic and hyperbolic, that is to say, a generally conservative variety of language as opposed to male speech, which is characterized by greater use of slang and open acceptance of innovation. Since Jespersen there have been many attempts to categorize the differences between male and female speech. In 1952, Orbis gathered a whole series of studies concerned precisely with this topic. However, it is only since the 1960 s, with the rise of sociolinguistics as a separate 
branch of linguistics based on relatively accurate statistical analyses and objective sociological information, that anything more than general impressionistic conclusions have been reached. Since William Labov's survey of New York speech published in 1966, there has been a whole spate of urban dialect surveys which have looked closely at sex differences in language. ${ }^{4}$ Although these surveys have brought to light a wealth of new, detailed information, in their general findings on male-female differences in language they have tended to support the conclusions of earlier, more impressionistic, studies. Also, it has been discovered that highly industrialized urban areas and primitive or rural communities differ very little in the ways males and females handle language. The general view seems to be that, allowing for such factors as social class, ethnic group, and age, female speech is more conservative and/or prestigious than male speech.

The observation of linguistic behaviour in different social situations has further enabled sociolinguists to conclude that women tend to use more prestige-forms than males, particularly as the formality of the situation increases. This point, first made by Labov (1966, p. 288), refers to MC females. Neither Labov nor, so far as I know, anyone since, has been able to say whether lower-class women are also more sensitive to social speech. Their evidence is not clear here. This strikes me as surprising because one only has to watch any television 'soap-opera' dealing with WC life to see that lower-class females are certainly thought to be more sensitive to sociolinguistic variables than their male counterparts. A comparison of Hilda Ogden's language with that of her husband, Stan, in the British television series Coronation Street, provides a typical example, and I am sure many more could be adduced in support of this view. I will return to this point when I deal with the Valladolid variables.

Some sociolinguistic surveys, it is true, have indicated that women do innovate where males do not. For exampie, a study published in 1966 by Levine and Crockett of postvocalic / $\mathrm{r} /$ in Hillsboro, North Carolina, showed that women constituted the vanguard of linguistic change. But in this instance the change represented a movement away from the older prestige-form towards a new national norm. Similarly, Suzanne Romaine's analysis of the same feature in Scottish English also revealed women to be the main initiators of change. But, again, the females concerned were members of the higher status groups and were introducing a new prestige-form, i.e. they were moving in the direction of RP. It would, therefore, appear that even when females spearhead linguistic change, it tends to be in the direction of a new prestige-form as, for example, when a local prestige-feature is rejected and a movement initiated towards a national norm or the standard language. For this reason, it is important to differentiate between the terms 'prestigious' and 'conservative', as they are used to describe female speech. Although they are the labels most frequently attached to female speech, they are not always to be understood synonymously.

Noteworthy amongst those linguists who have concluded that female speech is, indeed, more conservative and/or prestigious than male speech is Peter Trudgill. Trudgill (1974, pp. 94-5) does not find it at all surprising that women should view language differently from men, given the structure of Western industrial society and the role generally performed by women in it, and accounts for the difference in the following way. First, women are rated socially, for the most part, on how they appear, whereas men are rated by what they do. Significant, it would seem, is that the social class of women tends to be determined by that of their husband, if married, or often by that of their father, if they 
still live in their parents' home. Only if they work and live alone do women determine their own social class. Now, because the social position of males is automatically signalled by what they do, and because the position of women in society is still intimately connected with that of males, women can only personally signal their status by the way they appear. One of the things they do to appear refined, Trudgill suggests, is to use more 'correct' forms of language. Secondly, the roughness and toughness associated with the relative hardship of WC life has transmitted to WC speech connotations of masculinity. For example, when informants have listened to the taped voices of a male WC speaker and a male MC speaker, and then have been asked which of the two speakers they felt would come out on top in a street fight, they have invariably voted in favour of the WC speaker. This offers some idea of the close association between WC speech and the concept of masculinity, and also explains why WC speech often acquires a curious positive value amongst male speakers of all socio-economic groups. For this same reason, it is hardly surprising that women tend to shun WC speech forms and move, particularly in formal situations, towards the standard language. The use of such forms transmits to the female speaker a whole series of undesirable social characteristics, as does the use of coarse or obscene language. Hence the conservative and/or prestigious nature of female speech in general.

What seems clear from all this is that the majority of linguists accept not merely that the language of women is generally more 'correct' than that of men, but also, and perhaps more importantly, that its character is intimately bound up with the type of life they enjoy in society. Implicit in this view is the assumption that, depending on the relative strengths of the two arguments proposed by Trudgill to explain sex differences in language, a change in the kind of life women lead in society should logically be accompanied by some form of adjustment in their linguistic behaviour. ${ }^{5}$ Since the role of women in contemporary Spanish society is being radically transformed, one of the most interesting aspects of the Valladolid survey is the opportunity it provides of observing the extent to which this assumption is true. Unfortunately, a drawback of the Valladolid survey is the fact that it is the first sociolinguistic survey of the language of Old Castile, and, consequently, there are no data from which to draw comparisons. Nevertheless, I will present my results, such as they are, and compare and contrast them with those of sociolinguists in Britain and the USA. First, though, a discussion of the changing role of women in contemporary Spanish society is necessary.

\section{The role of women in Spanish society}

\section{(1) Franco Spain}

In 1931 the II Spanish Republic started taking definite steps towards the complete emancipation of women. Political franchise, the divorce law (1932), and the introduction of legal abortion in Catalonia, were just some of the concessions made as part of the liberating process. But with the overthrow of the Republic in 1936 and the subsequent establishment of the Franco regime, these concessionary laws were repealed. Coeducation, for example, which had been introduced by the previous government, was quickly abolished. The reason for this was that, according to the principles of the 'Movement', Franco's main political organ, women should receive a thoroughly separate religious education designed specifically to teach them their 'proper' roles in society as future wives and mothers. It was felt that the incorporation of women into the world of 
work would politicize them and weaken the family.unit, and to remove this danger they were taught that their place was in the home and their function to have lots of children. In this way, not only would it be less likely for them to become politicized, but also they would help deter their husbands from becoming involved in political or labour problems. In short, women became an important tool in the hands of the Francoists to preserve the dictatorial structure, and, as such, they were exploited. For instance, until 1972, a woman did not legally reach the age of majority until she was $25 \mathrm{yr}$ old, whilst a man acquired this privilege at the age of 21 . However, by the early 1970 s attitudes were beginning to change substantially with regard to the role of women in Spanish society.

\section{(2) Change in the 1970s}

Francisco Umbral, a keen observer of the contemporary Spanish scene, sums up the position of females in Spain today in the following way:

La española está hecha un lio. (. . .) La española no sabe si hacerse azafata, hippy, progre, madre de familia, enfermera o marxista. Los tres estamentos más vivos y conflictivos, hoy, en el pais, son, los jóvenes, las mujeres y el Colegio de Abogados de Madrid (Umbral, 1974, p. 11). ${ }^{6}$

In spite of the obvious irony, Umbral is making a serious point which is supported by the results of a whole series of sociological surveys performed in Spain during the 1970s. These surveys are general surveys of the whole country, but Valladolid, as a leading industrial area, can be expected to conform with the rest of industrial Spain. I propose now to look briefly at one or two points arising from these surveys which have particular relevance to the theme of this article.

(a) Work. According to Foessa (1970), in 1975 only 50\% of women who worked worked for economic reasons. The other $50 \%$ of the active female population worked mainly for one of three reasons. They either had a desire to practise a profession, to be useful in society or to 'realizarse como persona'. Now, whereas women, especially lowerclass women, had long since worked for economic reasons, the reasons just enumerated appear to characterize the 1970 s and, as might be expected, show a clear correlation with socio-economic class. Foessa calculated that $34 \%$ of middle middle-class and upper middle-class females worked to 'realizarse como persona'; $42 \%$ of 'profesionales libres' (UC females?) worked for the same reason; $63 \%$ of upper class and upper middle-class women, and $33 \%$ of middle middle-class women did not. work because they did not need the money. Given these figures, Foessa concluded that

'quienes trabajan en ocupaciones socialmente mejor consideradas y en las que existe una mayor posibilidad de realización personal son mucho más favorables a la incorporación de la mujer al mundo del trabajo' (1976, pp. 370-73).

Amando de Miguel, a sociologist at Madrid University, offers a statistical report of the growth of female activity in certain of the professional sectors from 1970-72 (1977, p. 129). The report can be tabulated as shown in Table 1 (the figures are percentages).

Table 1 .

\begin{tabular}{ccccc}
\hline & $\begin{array}{c}\text { Veterinary } \\
\text { surgeons }\end{array}$ & Dentists & Doctors & Pharmacists \\
\hline 1970 & 0.2 & 4.0 & 4.3 & 34.4 \\
1971 & 0.3 & 4.0 & 5.2 & 39.6 \\
1972 & 0.4 & 4.6 & 6.1 & 41.1 \\
$\%$ Growth & 100 & 14 & 42 & 20 \\
\hline
\end{tabular}


While these figures are in no way dramatic, they do reflect, over a very short period, the increasing number of women who are receiving a university education in fields which, with the exception of pharmacy, have traditionally been wholly peculiar to men.

(b) Education. In Spain, education is by far the most important single objective indicator of socio-economic class. Amando de Miguel (1977, p. 341) points out that, during the 1970 s, only $19.5 \%$ of those who studied Bachillerato Superior, and $10.2 \%$ of those who went to University in Old Castile came from WC backgrounds. In other words, $80 \%$ of Bachillerato students and $90 \%$ of university students in Old Castile in the 1970s were members of the middle and upper classes. This gives some idea of the close connexion between education and socio-economic class.

With regard to the position of females in the education system, María Angeles Durán (1977, p. 195) has observed that the proportion of young females extending their studies beyond the limits of compulsory education rose sharply in the 1970s, and Amando de Miguel (1977, pp. 312-13) has further indicated that female expansion in secondary and higher education is considerably greater than that of males. Foessa (1976, pp. 373 and 383) concluded from its survey that 'el grupo más favorable al trabajo extradoméstico de la mujer se da entre las jóvenes que estudian y trabajan', and, more importantly, that 'los mayores cambios, en lo que a su concepción del papel de la mujer se refiere, se dan entre las jóvenes que estudian'.

In view of the correiation between education and socio-economic class, it appears that the role of women in Spanish society is being questioned primarily by middle-class females.

(c) Attitudes. Attitudes to the role of women in Spain today are not only being revised by MC females. In 1975, Foessa attempted to elicit from Spaniards of both sexes, and all socio-economic groups and ages, their opinion concerning equal treatment and opportunities for women. It did this by asking them whether or not they agreed with the statement contained in Table 2 (1976, p. 387).

Table 2.

\begin{tabular}{lccccc}
\hline $\begin{array}{l}\text { One can allow a boy to return } \\
\text { home iate at night. A girl }\end{array}$ & & & & \\
must be assigned a time. & UC/UMC & MMC & LMC & WC \\
$\%$ in agreement & 37.6 & 47.9 & 51.4 & 61 \\
\hline
\end{tabular}

It seems logical to conclude from these figures that, as one ascends the social-class continuum, one finds greater support given to the idea of equal treatment for women. The working-classes remain the most resistant to change. The results of the survey may well reflect the greater effort made by young MC females to effect a change in attitudes in their homes.

(d) Summary. Several independent sociological surveys performed in Spain in the 1970s have shown that middle-class women have begun to increase significantly their participation in secondary and higher education, and their activity in the economy. This change seems to have been prompted by a desire on their part to assert their self- 
importance and to manifest their dissatisfaction with the role assigned to them over the past $40 \mathrm{yr}$. It is probably no coincidence that the re-emergence of the Feminist Movement, which is composed principally of MC intellectuals, also took place in the early 1970s. The progress made by MC women since then is undoubtedly reflected in the way in which MC, more particularly UMC, Spaniards in general support the idea of equal treatment for women, whereas the working classes remain reluctant to accept any change in the situation encouraged by the Franco regime.

\section{Types of variable}

In the Valladolid speech community, there are phonological variables of both 'fine' and 'sharp' stratificational types. A 'fine' stratificational variable is one which dissects the social-class continuum discreetly. It forms part of the language of speakers of all socio-economic groups and differs in its use from one speaker to another only in the frequency with which each of its variants occurs. The frequency of each variant will depend primarily on the formality of the situation and the social characteristics of the speaker. For example, in British society, with the possible exception of those areas designated $h$-less, like South Wales, the phonological variable $(h)$, i.e. the presence or absence of the aspirate, is found in the language of speakers of all socio-economic groups. However, the frequency of the prestige-variant, or presence of the aspirate, is normally much higher amongst the middle classes than amongst the working classes. But there is no specific point along the social-class continuum at which the frequency of the aspirate is suddenly increased dramatically. On the contrary, its frequency increases gradually and ( h $)$ can therefore be classified as a fine stratificational variable.

A 'sharp' stratificational variable, on the other hand, dissects the social-class continuum abruptly, cleanly separating one social group from another. In Valladolid, there are two types of sharp stratificational variable: the type peculiar to MC vallisoletanos which is not found as a variable in the language of the working classes; and the type which characterizes WC speech forming no part of the language of MC speakers. The variable $(m u y)$, for example, with its variants $[m w i ́(m u j]$ and $[m u]$ in expressions like ' $m u(y)$ bueno', is a variable only in WC speech. MC vallisoletanos use the form [mwi $\sim$ muj] exclusively. The same goes for MC variables which have variants peculiar to MC speech.

A predominance of fine stratificational variables in a community suggests a high degree of mobility up or down the social-class continuum, whereas a predominance of sharp stratificational variables suggests limited social mobility. The Valladolid speech community is characterized principally by sharp stratificational variables.

\section{WC variables}

\section{(1) The variable (muy)}

The variable $(m u y)$ has two variants: $[m w i \sim m u j]$ the prestige form, assigned the value (muy 1), and $[m u]$ the stigmatized form, assigned the value (muy 2). The behaviour of (muy) according to sex, socio-economic class, and contextual style is expressed statistically in Table 3. As will be the case for all the variables, the frequency of each variant of the variable is presented as a percentage score of the total number of occurrences of that variable observed among the different socio-economic groups in the various social contexts. 
Table 3. Variable (muy) by class, sex and style

\begin{tabular}{|c|c|c|c|c|c|c|}
\hline \multirow[b]{2}{*}{ Class } & \multirow[b]{2}{*}{ Sex } & \multirow[b]{2}{*}{ Variant } & \multicolumn{4}{|c|}{ Style } \\
\hline & & & $C S$ & RPS & WLS & MPS \\
\hline \multirow{4}{*}{ UMAC } & \multirow{2}{*}{$M$} & $m w i \sim m u j$ & 98 & 100 & 100 & 100 \\
\hline & & $m u$ & 2 & - & - & - \\
\hline & \multirow{2}{*}{$F$} & $m w i \sim m u j$ & 99 & 100 & 100 & 100 \\
\hline & & $m u$ & 1 & - & - & - \\
\hline \multirow{4}{*}{ LMC } & \multirow{2}{*}{$\mathrm{M}$} & $m w i \sim m u j$ & 92 & 100 & 100 & 100 \\
\hline & & $m u$ & 8 & - & - & - \\
\hline & \multirow[b]{2}{*}{ F } & meve & & $m$ & $m$ & \\
\hline & & mu & - & - & - & - \\
\hline \multirow{4}{*}{ UwC } & \multirow{2}{*}{$M$} & $m w i \sim m u j$ & 57 & 100 & 100 & 100 \\
\hline & & $m u$ & 43 & - & - & - \\
\hline & \multirow[b]{2}{*}{ F } & $m w i \sim m u j$ & 100 & 100 & 100 & 100 \\
\hline & & $m u$ & - & - & - & - \\
\hline \multirow{4}{*}{ LIVC } & M & $m w i \sim m u j$ & $\begin{array}{l}32 \\
68\end{array}$ & 92 & 100 & 100 \\
\hline & & & & & & \\
\hline & \multirow{2}{*}{ F } & $m w i \sim m u j$ & 73 & 100 & 89 & 100 \\
\hline & & $m u$ & 27 & - & 11 & - \\
\hline
\end{tabular}

Except for the anomalous score achieved by LWC females in WLS, stylistic variation is completely regular. Each social group reduces the frequency of (muy 2 ) as it moves from the informal to the formal end of the stylistic continuum. Social-class differentiation, however, is not entirely orthodox. Male informants -can indeed be ranked hierarchically according to socio-economic class, with LWC speakers showing the highest frequency of stigmatized forms in CS, and UMC speakers the lowest. But female informants depart from the pattern one might expect. In CS, LWC fernales are not only far more conservative than the males of their own social class, but also more conservative than the males of the UWC. Yet they still use (muy 2) considerably in this style. Females of the UWC and LMC are absent from the table for this variant, whilst UMC females are at least represented. The use of (muy 2 ) by U MC females, although seemingly insignificant, compares curiously with the complete absence of this variant in UWC and LMC female speech and has three possible explanations. First, it could be dismissed as a mere anomaly. Alternatively, and this is a view that I have taken eisewhere (Williams, in press), it could be seen as the incipient infiltration of a non-standard form into UMC female speech which, when taken along with their clearly unorthodox behaviour for a whole series of variables characterizing $\mathrm{MC}$ speech, might be thought to be yet another indication of the changing role of UMC females in contemporary Spanish society. The third possibility has to do with Trudgill's explanation of the conservative nature of female speech. He suggests that one of the reasons why women in general avoid WC linguistic features is because of the close association between the concept of masculinity and WC speech. It is clear from Table 3 that $(m u y)$ is not only characteristic of WC speech but aiso, more especially, of male WC speech, and it could, therefore, be argued that whereas UMC females, as we shall see, do appear to reflect their changing role in society by means of marked unorthodox handling of MC variables, the low score they achieve for $(m u y)$ reveals their 
reluctance to use WC variables because of the close association between these and the concept of masculinity. Only time will tell which, if any, of these explanations is accurate.

\section{(2) The variable (sc)}

The variable ( $s c)$ as found in words like 'asco', possesses three variants in the Valladolid speech community, which can be arranged hierarchically in the following way: (sc 1) or [sk]; (sc 2) or [hk]; and (sc 3) or [xk]. Table 4 represents the differentiation of (sc) according to socio-economic class, sex and style. The differentiation of (sc) according to sex illustrates how (sc 2) and (sc 3) are not only peculiar to WC speech but are, as in the case of $(m u y)$, predominantly characteristic of the language of WC males. However, even among this group the position of (sc 1) remains reasonably secure.

Table 4. Variable (sc) by class, sex and style

\begin{tabular}{|c|c|c|c|c|c|c|}
\hline \multirow[b]{2}{*}{ Class } & \multirow[b]{2}{*}{ Sex } & \multirow[b]{2}{*}{ Variant } & \multicolumn{4}{|c|}{ Style } \\
\hline & & & $\mathrm{CS}$ & RPS & WLS & MPS \\
\hline \multirow{6}{*}{ UMC } & \multirow{3}{*}{ M } & sk & 99 & 100 & 100 & 100 \\
\hline & & $h k$ & - & - & - & - \\
\hline & & $x k$ & 1 & - & - & - \\
\hline & \multirow{3}{*}{$\mathrm{F}$} & & & & 100 & 100 \\
\hline & & $h k$ & - & - & - & - \\
\hline & & $x k$ & - & - & - & - \\
\hline \multirow{6}{*}{ LMC } & \multirow{3}{*}{ M } & sk & 100 & 100 & 100 & 100 \\
\hline & & $i k$ & - & - & - & - \\
\hline & & $\checkmark k$ & - & - & - & - \\
\hline & \multirow{3}{*}{$\mathrm{F}$} & $s k$ & 100 & 100 & 100 & 100 \\
\hline & & $h k$ & - & - & - & - \\
\hline & & $x k$ & - & - & - & - \\
\hline \multirow{6}{*}{ UWC } & \multirow{3}{*}{ M } & sk & 86 & 100 & 100 & 100 \\
\hline & & $h k$ & 6 & - & - & - \\
\hline & & $x k$ & 8 & - & - & - \\
\hline & \multirow{3}{*}{ F } & & & & & \\
\hline & & sk & 100 & 100 & 100 & 100 \\
\hline & & $x k$ & - & - & - & $\overline{-}$ \\
\hline \multirow{7}{*}{ LWC } & \multirow{4}{*}{$M$} & & & & & \\
\hline & & sk & 59 & 95 & 100 & 100 \\
\hline & & $h k$ & 8 & - & - & - \\
\hline & & $x k$ & 33 & 5 & - & - \\
\hline & \multirow{3}{*}{ F } & $s k$ & 82 & 100 & 100 & 100 \\
\hline & & $h k$ & 12 & - & - & - \\
\hline & & $x k$ & 6 & - & - & - \\
\hline
\end{tabular}

Close examination of the way in which the WC variables $(m u y)$ and $(s c)$ are handled in Valladolid reveals that WC females are more sensitive to social speech than their male counterparts and are much less likely than these to use non- or sub-standard linguistic features. Whereas Labov's data are confusing here, the results of the Valladolid survey are quite clear. 
MC variables?

(1) The variable (-cc-)

The variants of $(-c c-)$ arranged hierarchically are $(-c c-1)$ or $[k \theta \sim \gamma \theta]$ and $(-c c-2)$ or $[\theta \theta \sim \theta]$. The alternative pronunciations of the prestige form could arguably be classified as different variants and, in fact, separate scores were computed for both forms and are included in Table 5. However, use of $[k \theta]$ or $[\gamma \theta]$ depends, for the most part, on the speed of discourse and while this could be seen to be related in some way to formality and emphasis, it makes much more sense, for present purposes, to group them together in opposition to (-cc-2), which is clearly the stigmatized variant. In this way, general patterns of co-variation will be easier to identify. This is the sort of coarsening of the data to which I referred above and which will hold for the prestige forms of all the MC variables to be looked at here.

Table 5. Variable (cc) by class, sex and style

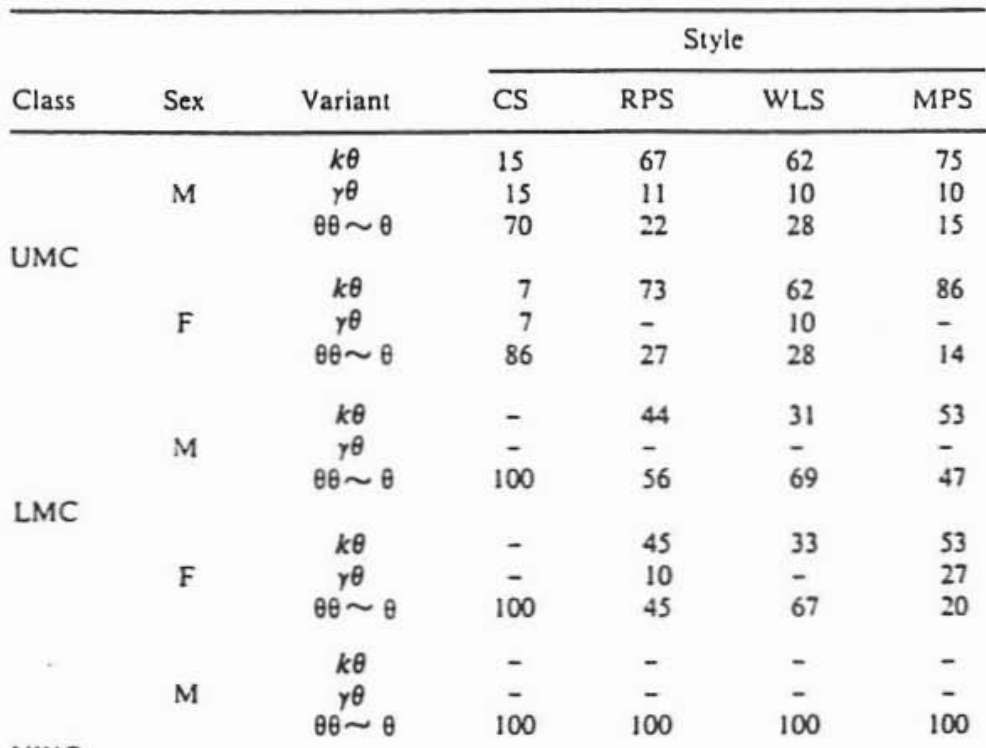

UWC

LWC

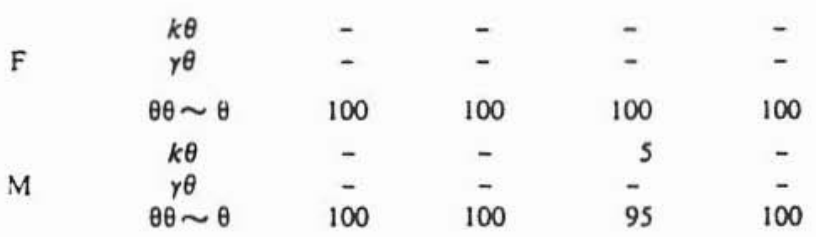

\begin{tabular}{|c|c|c|c|c|c|}
\hline & $k \theta$ & - & - & - & - \\
\hline & $r \theta$ & - & - & - & - \\
\hline & $\theta \theta \sim \theta$ & 100 & 100 & 100 & 100 \\
\hline
\end{tabular}

Table 5 reveals the co-variation of this variable with socio-economic class, sex and contextual style. UMC females use the stigmatized variant or $(-c c-2)$ more often than their male counterparts in CS and in RPS. In WLS and MPS, however, both groups achieve almost identical scores for this variant. Males and females of the LMC use (-cc-2) invariably in CS, with females shifting to become slightly more conservative in more 
continuum, UMC speakers shift normally only as far as WLS. They then suddenly reverse the direction of stylistic variation between this point and MPS, thereby signalling that they may be beginning to question established values.

(3) The variable $(-x-)$

In words like 'examen', the variable $(-x-)$ has the variants $(-x-1)$ or $[k s \sim y s]$ and $(-x-2)$ or $[s]$. Table 7 illustrates how the females of both classes show' a higher incidence of $(-x-2)$ than their male counterparts in RPS, WLS and MPS. In CS, there is no difference between male and female scores for this variant. Once again, then, MC females generally display a greater disregard for traditional, prestige forms than the males of their respective social classes.

Table 7. Variable $(-x-)$ by class, sex and style

\begin{tabular}{|c|c|c|c|c|c|c|}
\hline \multirow[b]{2}{*}{ Class } & \multirow[b]{2}{*}{ Sex } & \multirow[b]{2}{*}{ Variant } & \multicolumn{4}{|c|}{ Styie } \\
\hline & & & $\mathrm{CS}$ & RPS & WLS & MPS \\
\hline & & ks & 25 & 93 & 84 & 75 \\
\hline & $M$ & ys & - & - & 9 & 17 \\
\hline & & $s$ & 75 & 7 & .7 & 8 \\
\hline \multicolumn{7}{|l|}{ UMC } \\
\hline & & ks & 18 & 71 & 64 & 55 \\
\hline & $\mathrm{F}$ & rs & 7 & 4 & 9 & 20 \\
\hline & & $s$ & 75 & 25 & 27 & 25 \\
\hline & & ks & - & 33 & 43 & 42 \\
\hline & $M$ & ys & - & 7 & - & - \\
\hline & & $s$ & 100 & 60 & 57 & 58 \\
\hline \multicolumn{7}{|l|}{ LMC } \\
\hline & & ks & - & - & 21 & 25 \\
\hline & $F$ & ys & - & 7 & 3 & - \\
\hline & & s & 100 & 93 & 76 & 75 \\
\hline & & ks & - & - & 12 & - \\
\hline & M & ys & - & - & - & - \\
\hline & & 5 & 100 & 100 & 88 & 100 \\
\hline \multicolumn{7}{|l|}{ UwC } \\
\hline & & ks & - & 7 & - & 9 \\
\hline & $\mathrm{F}$ & ys & - & - & - & - \\
\hline & & 5 & 100 & 93 & 100 & 91 \\
\hline & & ks & - & - & - & - \\
\hline & M & ys & - & - & - & - \\
\hline \multirow{2}{*}{\multicolumn{5}{|c|}{ LWC }} & 100 & 100 \\
\hline & & & - & - & & - \\
\hline & F & ys & - & 7 & $\overline{-}$ & $\overline{-}$ \\
\hline & & 5 & 100 & 93 & 100 & 100 \\
\hline
\end{tabular}

(4) The variable (ct)

The variants of (ct) as this variable occurs in words like 'acto' are (ct 1) or $[k t \sim \gamma t]$, (ct 2) or $[t t \sim t]$, and $(c t 3)$ or $\left[\theta t \sim{ }^{-} t\right]$. As Table 8 shows, RPS has been replaced, in this instance, by RWLS or Rapid Word-List Style. This is because $(c t)$ was discovered too late during fieldwcrk for occurrences of the variable to be embedded into the reading passage. The scores in Table 8 seem to indicate that RWLS was not entirely unsuccessful in representing some kind of intermediate point along the stylistic continuum between CS and WLS. 
Table 8. Variable ( $c t$ ) by class; style and sex

\begin{tabular}{|c|c|c|c|c|c|c|}
\hline \multirow[b]{2}{*}{ Class } & \multirow[b]{2}{*}{ Sex } & \multirow[b]{2}{*}{ Variant } & \multicolumn{4}{|c|}{ Style } \\
\hline & & & CS & RWLS & WLS & MPS \\
\hline \multirow{8}{*}{ UMC } & \multirow{4}{*}{ M } & $k t$ & 39 & 93 & 92 & 100 \\
\hline & & $\boldsymbol{r t}$ & 10 & 7 & .8 & - \\
\hline & & $t \sim \sim t$ & 7 & - & - & - \\
\hline & & $\theta t \sim 2$ & 44 & - & - & - \\
\hline & \multirow{4}{*}{ F } & $k t$ & 40 & 75 & 70 & 60 \\
\hline & & $\gamma t$ & 19 & 4 & 10 & - \\
\hline & & $t \tau \sim t$ & - & - & 5 & - \\
\hline & & $\theta t \sim g_{t}$ & 41 & 21 & 15 & 40 \\
\hline \multirow{8}{*}{ LMC } & \multirow{4}{*}{$M$} & $k t$ & 4 & 33 & 45 & 17 \\
\hline & & $r t$ & 4 & - & - & - \\
\hline & & $t z \sim t$ & 4 & $\overline{67}$ & 10 & $=$ \\
\hline & & of & 00 & or & 45 & os \\
\hline & \multirow{4}{*}{$\mathrm{F}$} & $k t$ & 22 & 26 & 27 & 17 \\
\hline & & $y t$ & 5 & 7 & 9 & 17 \\
\hline & & $t \sim t$ & 7 & 7 & - & - \\
\hline & & $\theta t \sim \sim_{t}$ & 66 & 60 & 64 & 66 \\
\hline \multirow{8}{*}{ UWC } & \multirow{4}{*}{ M } & $k t$ & - & - & - & - \\
\hline & & $y t$ & - & - & - & - \\
\hline & & $t t \sim t$ & 10 & - & $=$ & $\overline{-}$ \\
\hline & & $\theta t \sim s t$ & 90 & 100 & 100 & 100 \\
\hline & \multirow{4}{*}{$\mathbf{F}$} & $k t$ & - & - & 8 & - \\
\hline & & $y t$ & - & - & - & - \\
\hline & & $t \sim t \sim t$ & - & - & 8 & - \\
\hline & & $\theta t \sim \sim^{2}$ & 100 & 100 & 84 & 100 \\
\hline \multirow{8}{*}{ LWC } & \multirow{4}{*}{ M } & $k t$ & - & - & 8 & - \\
\hline & & $r t$ & - & - & $\overline{0}$ & - \\
\hline & & $t \sim t$ & 6 & - & 8 & - \\
\hline & & $\theta t \sim g_{t}$ & 94 & 100 & 84 & 100 \\
\hline & \multirow{4}{*}{ F } & $k t$ & - & - & - & - \\
\hline & & $y t$ & - & - & - & - \\
\hline & & $t t \sim t$ & 14 & - & - & - \\
\hline & & $\theta t \sim \theta_{t}$ & 86 & 100 & 100 & 100 \\
\hline
\end{tabular}

With the exception of CS, UMC females use (ct 3 ) more than UMC males in all contextual styles. They also reverse the direction of style-shifting between WLS and MPS and this may well suggest that they question traditional, prestige values. UMC males, on the other hand, are extremely conservative in their handling of $(c t)$ and only use non-standard forms in CS. In this way, they reveal emphatically their support of (ct 1$)$.

In contrast to UMC behaviour for this variable, LMC females are, for the most part, more conservative than LMC males. However, whereas the males of this class show a similar, if not identical, pattern of stylistic variation to that of UMC females, LMC females vary their handling of ( $c t$ ) hardly at all from one social context to another.

\section{Conclusion}

The data supplied in Tables 3-8 allow the following conclusions to be drawn:

(1) The behaviour of WC variables in Valladolid clearly demonstrates that WC females 
are, indeed, sensitive to social speech. They regularly display more frequent use of prestige variants than their male counterparts and reduce dramatically the number of stigmatized forms they use as they move from CS to RPS. The Valladolid data contrast sharply with Labov's inconclusive findings here.

(2) UMC females generally show themselves to be rather less concerned to preserve traditional, prestige features than the males of their social group. This lower level of concern is manifested in their willingness often to use a higher proportion of non-standard forms than UMC males, especially in formal contexts, and in their frequent reversal of the pattern of stylistic variation between WLS and MPS. I have argued above that this reversal in the direction of stylistic variation responds to the action of the 'Cursi-Paleto' dialectic and indicates that established values are being questioned. The effects of the dialectic, it is true, are not limited to UMC females and extend to UMC males and LMC speakers. But UMC fernales are the group most often affected. Occasionally, LMC females also show themselves to be more radical than the males of their social class, but the extent of their unorthodoxy is considerably less than that of UMC females. Thus, in terms of phonological behaviour, the most radical social group in Valladolid appears to be that of UMC females. This seems entirely consonant with the fact that UMC women are spearheading the changing role of women in contemporary Spanish society and establishes yet another clear link between linguistic and social behaviour.

(3) According to Trudgill (1974, pp. 94-95), women use more 'correct' forms of language than men because they are rated socially on 'how they appear' rather than by 'what they do', and because of the close association between WC speech and the concept of masculinity. Implicit in the first of these two explanations is the assumption that a change in the role of women which caused them to be rated socially by 'what they did' rather than on 'how' they appeared' could conceivably be accompanied by an adjustment in their linguistic behaviour, i.e. by a tendency for them to rely less on 'correct' language to signal their status. On the other hand, it would not be illogical to infer from the second point advanced by Trudgill that it alone might be sufficient not only to encourage women to avoid using WC features but also to deter them, to a greater or less extent, from relaxing their language in this direction regardless of any change in their role or status in society. Is it at all possible that either of Trudgill's explanations could render the other redundant? The results of the Valladolid survey demonstrate that certain MC females appear to have adjusted their linguistic behaviour in response to changes in their role in Spanish. society. This adjustment takes its clearest form in the relatively high proportion of non. standard variants they use, particularly in formal styles, for a whole series of MC variables, and in their reversal of the pattern of stylistic variation for a number of these variables between WLS and MPS. This suggests that the close connexion between WC speech and masculinity is insufficient to nullify all the possible linguistic effects of a change in female social behaviour. Many MC females in Valladolid are showing signs of rejecting established linguistic norms and of moving in the direction of non-prestig: forms. It is important to remember, however, that the linguistic features so far referre: to are variables only in MC speech and one may well ask whether MC females give an sign of acquiring features of WC speech. Briefly, UMC females do show very limited us of (muy 2). In Table 3, they achieve a very low incidence of this variant, which is a featur mainly characteristic of male WC speech. The significance of this low score is not clea: but should not be dismissed as anomalous until sufficient time has elapsed in which th: 
progress or demise of (muy 2) amongst MC females can be observed. If over the next decade or two MC females continue to push for a more active role in society, and if this continues to be reflected in their linguistic behaviour, it should be possible to arrive at some firm conclusions concerning (muy). If the incidence of (muy 2) does not increase amongst MC females or disappears, then its use by UMC females in Table 3 may be seen as an anomaly. This would mean that the identification of WC speech with the idea of masculinity does not deter MC females from adjusting their linguistic behaviour away from the standard language in reponse to changes in their social behaviour, but that it does seem to prevent them from adopting features which are characteristic of male WC speech. In other words, shifts in female linguistic behaviour which mirror changes in their social behaviour are a reality but appear subject to certain binding sociolinguistic constraints. On the other hand, a significant increase in the frequency of (muy 2) amongst MC females over the same time-scale would be a clear indication that, in Valladolid at least, the associations of masculinity attached to WC language are rather less important in helping to determine female speech patterns than the actual role women perform in society. We must wait to find out the answer.

(4) Finally, the use of the Self-Evaluation Test allowed Labov (1966), in his New York survey, and Trudgill (1974), in his study of Norwich English, to discover the existence of certain covert linguistic norms operating discreetly, but nevertheless powerfully, below the level of public awareness and in opposition to the overtly recognized prestige forms reflected in the uniform patterns of stylistic variation shared by the respective speech communities. According to both linguists, high covert prestige is associated with WC speech forms by the males of all socio-economic groups. Presumably, this is because of the close connexion between the idea of masculinity and WC speech which Trudgill has pointed to. However, Trudgill $(1975$, p. 103) goes further than Labov, claiming that in Norwich 'for male speakers and for female speakers under 30, non-standard WC speech forms are highly valued, although these values are not usually overtly expressed'. ${ }^{8}$ In Valladolid, female speakers under 30 , who are members of the highest socio-economic group, can be seen to be moving away from traditional norms in the direction of substandard or non-prestige features. With the exception of (muy), it could be argued that these forms are not clearly characteristic of WC speech. Nevertheless, what is incontrovertible is that young UMC females are rejecting traditional, prestige forms and are moving towards what hitherto have been non- or sub-standard speech-forms and, curiously, this movement is overtly expressed in their patterns of stylistic variation.

Acknowledgements-1 would like to thank Steven Dodd of Exeter University for his advice concerning the presentation of data, and Professor Keith Whinnom, also of Exeter University, for reading a draft of the manuscript and making many useful suggestions.

\section{NOTES}

1 This article was presented in the form of a paper at the IX Romance Linguistics Seminar held at Cambridge University on 5 and 6 January, 1981.

2 Detailed explanation of the methodology used evidently cannot be given here. However, a few things such as the number of informants interviewed and the nature of certain aspects of the questionnaire do need to be mentioned. Six months before the definitive survey began 1 performed a small pilot survey involving 12 informants. This was intended to test the questionnaire and to identify tentatively a number of phonological variables and their variants. In the definitive survey, 29 informants were interviewed, 13 male and 16 female. 
Unfortunately, 3 of these interviews could not be used. The tape-recording of one Lower Middle-class (LMC) female was faulty; one LMC male, although born and bred in Valladolid, had a very thick dialect accent ane was therefore exciuded from the average scores computed for his socio-economic group; and one Uppe: Working-class (UWC) female consistentiy achieved scores characteristic of Upper Middle-class (UMC) females. She too was exeluded from the average scores for her socio-economic group. The last two of these will at some stage require separate analysis. The final total of 26 informants for the definitive survey represents one agegroup, four social classes, and both sexes. This number compares not unfavourably with Trudgill's $6 C$ informants in Norwich who represent seven age-groups, five social classes, and both sexes (see Trudgill, 1974).

The more formal sections of the questionnaire consisted of various word lists and a continuous passage, all of which informants were invited to read. The reading passage of some 274 words was composed by myself anc checked by a native speaker of Spanish. The passage contained examples of the relevant phonological variable and was written in a conversational style. Of the word lists, MPS contained 65 pairs, WLS 137 lexieal items, ane RWLS (to be read rapidly) 43 items. The following examples are from MPS but the second member of eact pair, which contains the relevant variable, could also serve to illustrate the nature of WLS and RWLS:

for (muy), musulmán-muy sucio; for (sc) eje-es que;

for ( $x$ cons), escoger-excomulgar; for $(-x-)$, desistir-existir;

for (-ce-), nación-fracción; and for (ct), azteca-actuar.

The matching of pairs was only difficult in the case of $(s c)$. Here the diffieulty lay not in matching the stigma. tized variant but in matching the phonetic environment. Consequently, this is the least satisfactory of the pairs However, since the stigmatized variant of this variable hardly occurred outside CS as the relevant table shows. this need cause no concern.

One more point needs to be made with regard to MPS. Because of the very close link between orthography ane pronunciation in standard Spanish, it should be remembered that informants inevitably had to make a consciouchoice between the variants of a variable in this style. Given this, one might expect the spelling of the forr containing the variable to have inclined the reader towards the traditional, prestige form and it is, therefore, al the more striking when informants rebel against orthography and choose an alternative pronunciation. The: selection of variants in this style can only be seen as being conscious and thus explains why I have seen th: contert as an important indicator of the 'Cursi-Paleto' dialectic (see below). It is conceivable that MPS ma. well prove less heipful in identifying sociolinguistic trends where the link between orthography and pre nunciation is not so close and this perhaps explains why neither Labov nor Trudgill included the results for thi. style in their graphs. In private correspondence to me, Trudgill indicated that MPS had produced heterc. geneous data in Norwich.

3 If it is true, as Labov appears to claim, that it is the highest status group in a speech community which deter. mines the linguistic patterns which are overtly recognized as being prestigious in that community, then it seerr: logical to assume that this social group must also feel in a position to be able to reject traditional norms frot: time to time and create new ones which the rest of the community, in public at least, will eventually feel oblige. to aim for. This is hardly new. Where Labov and I part company, however, is in the matter of attitudes towarc. the competing variants of variables within the speech community. My views on linguistic change, the nature 0 the speech community, and overt attitudes to linguistic variables in the speech community require more detaile explanation than can be afforded here. All I can say for the moment is that I sympathize with much of what expressed in Bailey (1973), Bickerton (1971, pp. 457-92), Knowles (1978, pp. 80-90) and Romaine (1982). I ar: grateful to Dr Max Wheeler of Liverpool University for the reference to Knowies' work on Scouse.

4 These include Shuy et al. (1967), Wolfram (1969), and Trudgill (1974). Research has also been performed 2. smaller communities e.g. Anshen (1969), Levine and Crockett (1966) etc.

5 I propose to say something below about the relative strengths of the two arguments supplied by Trudgill : explain the 'correct' or 'prestigious' nature of female speech.

6 'Spanish women are in a muddle (. . . .) They don't know whether to become hostesses, hippies, trendie mothers, nurses, or Marxists. The three most radical sections of our society today are made up of the younE women and the Madrid College of Law.' (My transiation)

7 Whereas, in theory, MC variables are, by definition, variables only in MC speech, in practice things are $\mathrm{BC}$ always quite so clear-cut. Occasionally, the odd WC informant achieved less than the expected maximu: informal score possible for a particular variable and these scores are included in the relevant tables where this the case. However, such scores can usually, if not always, be explained in one of two ways. First, spelling pr nunciations account for the larger part of them. The low level of literacy amongst most WC Spaniards mea. that they often tend to read words one letter at a time. This obviously makes spelling pronunciations both almt inevitabie and relatively easy to identify. Secondly, in a small number of cases deviant WC pronunciation $e=$ be explained in terms of stereotypes. For instance, WC speakers tend to produce (ct 3 ) systematically when the encounter ( $c t$ ). But there are a few stereotyped cases like the expression 'barrio de la Victoria' in which aime all speakers of Valladolid Spanish, regardless of socio-economic class, tend to produce consistently (ct 2) 
spontaneous conversation. The occurrence of stereotypes, then, can obviously cause WC speakers to achieve less than the maximum informal scores expected for MC variables. Also, as the WC scores and their disposition in the tables show, it is impossible to identify any sort of correlation between the prestige form and social context. This would seem to support the notion that what we have here are deviant scores and 1 , therefore, see no real argument for re-classifying the MC variables as fine variables rather than sharp ones.

It is unfortunate that the limited number of informants interviewed in the Norwich survey did not allow for a breakdown to be made of this group of young fermales according to socio-economic class.

\section{REFERENCES}

ANSHEN, F. 1969 Speech variation among Negroes in a small southern community. Unpublished doctoral dissertation, New York University.

BAILEY, C. J. 1973 Variation and Linguistic Theory. Center for Applied Linguistics, Washington.

BICKERTON, D. 1971 Inherent variability and variable rules. Foundations of Language 7, 457-92.

DURAN, M. A. 1977 Dominación, sexo y cambio social. Edicusa, Madrid.

FOESSA, F. 1976 Estudios sociológicos sobre la situación social de España 1975. Fundación Foessa, Madrid.

JESPERSEN, O. 1922 Language: Its Nature, Development, and Origin. Allen and Unwin, London.

KNOWLES, G. O. 1978 The nature of phonological variables in Scouse. In Trudgill, P. (Ed.), Sociolinguistic Patterns in British English, pp. 80-90. Edward Amold, London.

LABOV, W. 1966 The Social Stratification of English in New York City. Center for Applied Linguistics, Washington.

LEVINE, L. and CROCKETT, H. J. 1966 Speech variation in a Piedmont community: postvocalic r. In Liebersen, S. (Ed.) Explorations in Sociolinguistics, pp. 76-98. Indiana University Press, Bloomington.

MIGUEL, A. de 1977 Recursos humanos, clases y regiones en España. Edicusa, Madrid.

ORBIS, 1952 Vol. 1 Centre International de Dialectologie Générale, Louvain.

ROMAINE, S. 1978 Postvocalic /r/ in Scottish English: Sound Change in Progress? In Trudgill, P. (Ed.), Sociolinguistic Patterns in British English, pp. 144-157. Edward Arnold, London.

ROMAINE, S. 1982 Socio-historical Linguistics: Its Status and Methodology. Cambridge University Press. Cambridge.

SHUY, R., WOLFRAM, W. and RILEY, W. K. 1967 Final Report, Project 6-1347. Office of Education, Washington.

TRUDGILL, P. 1974 The Social Differentiation of English in Norwich. Cambridge University Press, Cambridge.

TRUDGILL, P. 1975 Sex, covert prestige and linguistic change in the urban British English of Norwich. In Thorne, B. and Henley, N. (Eds) Language and Sex: Difference and Dominance, pp. 88-104. Newbury House, Rowley.

UMBRAL. F. 1974 Las españolas. Planeta, Barcelona.

UMBRAL, F. 1978 Ramón y las vanguardias. Espasa-Calpe, Madrid.

WILLIAMS, L. (In press) Two features of working-class phonology in Valladolid. Orbis.

WOLfRAM, W. A. 1969 A Sociolinguistic Description of Detroit Negro Speech. Center for Applied Linguistics, Washington. 